\author{
Joke Beuten - Raoul C. M. Hennekam \\ Bernadette Van Roy $\cdot$ Kathelijne Mangelschots \\ James S. Sutcliffe - Dicky J. J. Halley \\ Frederic A. M. Hennekam - Arthur L. Beaudet \\ Patrick J. Willems
}

\title{
Angelman syndrome in an inbred family
}

Received: 8 June 1995/Revised: 22 August 1995

\begin{abstract}
Angelman syndrome (AS) is characterized by severe mental retardation, absent speech, puppet-like movements, inappropriate laughter, epilepsy, and abnormal electroencephalogram. The majority of AS patients $(\approx 65 \%)$ have a maternal deficiency within chromosomal region $15 q 11-q 13$, caused by maternal deletion or paternal uniparental disomy (UPD). Approximately $35 \%$ of AS patients exhibit neither detectable deletion nor UPD, but a subset of these patients have abnormal methylation at several loci in the $15 q 11-q 13$ interval. We describe here three patients with Angelman syndrome belonging to an extended inbred family. High resolution chromosome analysis combined with DNA analysis using 14 marker loci from the $15 q 11-q 13$ region failed to detect a deletion in any of the three patients. Paternal UPD of chromosome 15 was detected in one case, while the other two patients have abnormal methylation at D15S9.D15S63, and SNRPN. Although the three patients are distantly related, the chromosome 15q11-q13 haplotypes are different, suggesting that independent mutations gave rise to AS in this family.
\end{abstract}

\section{Introduction}

Angelman syndrome (AS) is a neurological disorder characterized by severe mental retardation, absence of speech,

J. Beuten - B. Van Roy - K. Mangelschots - P. J. Willems (ه)

Department of Medical Genetics,

University of Antwerp - UIA, B-2610 Antwerp, Belgium

Tel.: +323-8202570; Fax +323-8202566

R. C. M. Hennekam

Institute of Human Genetics and Department of Pediatrics,

University of Amsterdam, Amsterdam, The Netherlands

J. S. Sutcliffe - A. L. Beaudet

Department for Molecular and Human Genetics,

Baylor College of Medicine and Howard Hughes Medical Institute, Houston, USA

D. J. J. Halley

Department of Clinical Genetics,

Erasmus University Rotterdam, The Netherlands

F. A, M. Hennekam

Clinical Genetics Center, Utrecht, The Netherlands paroxysms of laughter, a puppet-like ataxic gait, microcephaly, and epilepsy (Willems et al. 1987; Williams et al. 1989; Clayton-Smith and Pembrey 1992). The incidence of AS has been estimated to be around 1/20000 (ClaytonSmith and Pembrey 1992). In about $65 \%$ of AS patients, an interstitial deletion within 15 q11-q13 or paternal uniparental disomy of chromosome 15 can be detected by cytogenetic and/or molecular methods (Hamabe et al. 1991 b; Malcolm et al. 1991; Beuten et al. 1993). The deletions are found exclusively on the maternal chromosome. Prader-Willi syndrome (PWS), a phenotype distinct from AS, results from paternal-specific deficiency in $15 \mathrm{q} 11-$ q13, caused most frequently (in $70 \%$ of the patients) by deletion (Butler 1990; Hamabe et al. 1991 a; Robinson et al. 1991; Nicholls 1993). Most of the remaining 30\% of PWS patients are found to have maternal uniparental disomy (UPD), however, paternal UPD is rare in AS.

Alternative genetic mechanisms have been proposed to explain the occurrence of AS in the remaining cases where neither a deletion nor UPD could be detected. Linkage analysis in the families with multiple AS patients reported by Wagstaff et al. (1993) and Meijers-Heijboer et al. (1993) yielded positive lod scores, indicating linkage of AS to a locus in the 15q11-q13 region. Pedigree analysis and linkage analysis of these families indicate autosomal dominant inheritance of AS modified by genomic imprinting, such that AS is expressed when the mutation is inherited maternally, but the mutation is asymptomatic when transmitted paternally (Clayton-Smith et al. 1992; Wagstaff et al. 1993; Meijers-Heijboer et al. 1993; Nelen et al. 1994). A fourth class of AS patients is characterized by absence of the classical deletion and UPD, but with an abnormal methylation pattern of some $15 q 11-q 13$ loci. AS in these patients has been proposed to result from mutations in a proximal $15 \mathrm{q}$ imprinting region (imprinting mutations) (Glenn et al. 1993 a; Horsthemke et al. 1994; Reis et al. 1994 a, b; Sutcliffe et al. 1994). Recently, small deletions between D1.5S63 and SNRPN (the small nuclear ribonucleoprotein locus) have been identified in some of these patients, suggesting that the imprinting mutation is caused by deletion of an imprinting region in 15q11-q13 (Buiting et al. 1995). 
We report here three AS patients belonging to an extended, highly inbred, Dutch family. Cytogenetic and molecular analysis failed to reveal deletion in any of the three patients. One case demonstrated paternal isodisomy of chromosome 15, and the two other cases showed an abnormal methylation pattern of three different loci in the AS region.

\section{Materials and methods}

Patients

The three AS patients studied in this report were diagnosed by an experienced clinical geneticist (R.C.M.H.). The pedigree (Fig. 1 A) reveals a significant inbreeding and all of the parents of the three probands are descended from three ancestral couples. As the surnames of two pairs of these ancestors (I1/I3 and I2/I4) are the same, further consanguinity may well be present. The clinical criteria for diagnosis were: severe mental retardation, (nearly) absent

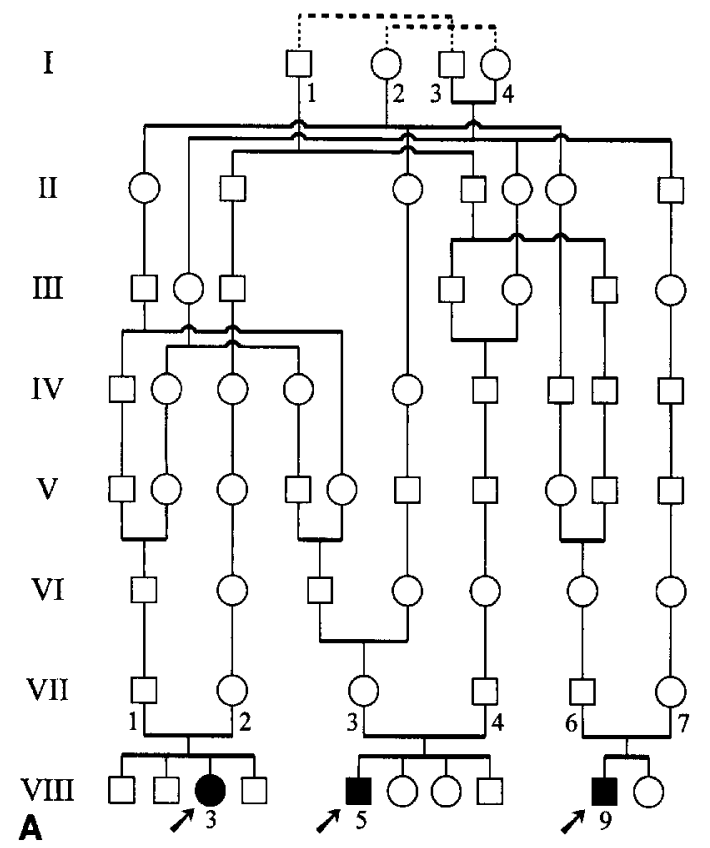

speech, ataxia, hyperactivity, bursts of laughter, brachycephaly, macrostomia, and prognatism (Fig. 1 B). Seizures were present in two patients, and characteristic electroencephalogram changes in all three. Terminal deletion of chromosome $16 \mathrm{p}$, a condition with some similar clinical features and thalassemia, was excluded by hemoglobin analysis (Wilkie et al. 1990).

\section{Cytogenetic and molecular studies}

High-resolution chromosome analysis was performed using Giemsa-trypsin banding on peripheral blood lymphocytes of the three AS patients, with special attention paid to chromosome 15 .

Genomic DNA of the patients and their parents was extracted either directly from peripheral blood leukocytes or from EpsteinBarr virustransformed lymphoblastoid cells. Southern blot analysis was performed according to standard procedures. The following chromosome $15 q 11-q 13$ DNA probes recognizing restriction fragment length polymorphisms (RFLPs) were used for deletion analysis: pIR4-3R/D15S11, pTD189-1/D15S13, pTD3-21/DI5S10, 28\$3$\mathrm{H} 3 / G A B R B 3$, pIR 10-1/D15S12, pCMW-1/D15S24, and the telomeric marker cMS620/D15S86. Polymerase chain reaction (PCR) amplification was performed for dinucleotide repeats at $D 15510$ (Lindeman et al. 1991), DISS11, D15S113, GABRB3 (the $\gamma$-aminobutyric acid $\beta$ receptor locus, Mutirangura et al. 1993 a), D15S13 (Mutirangura et al. 1993 b), D15S63 (Wagstaff et al. 1993), D15S97, D15S122, D15S128, D15S156 (Beckmann et al. 1993), D15S229E (Sutcliffe et al. 1994), and D1SS210 (Gyapay et al. 1994).

\section{Methylation analysis}

DNA isolated from peripheral blood leukocytes was digested with a combination of conventional and methylation-sensitive restriction enzymes, separated in a $0.8 \%$ agarose gel, and analyzed by Southern blot hybridization using probes pML34, PW71 or exon $\alpha$ of SNRPN. For both pML34 (B. Horsthemke, personal communication) and PW71 (Dittrich et al. 1992) a combination of the enzymes HindIII and HpaII was used, and a double digestion with $X b a I$ and $N o t I$ was used for the analysis of the SNRPN CpG island (Sutcliffe et al. 1994; Beuten et al. 1995).

Fig. 1 A Pedigree of the family analyzed in this study. The parents of patient VIII-3, VIII-5, and VIII-9 all originate from three ancestral couples. The stippled lines in generation I indicate that these couples were probably related as they carry the same family names. B Photographs of the three patients VIII-3, VIIl-5, and VIII-9
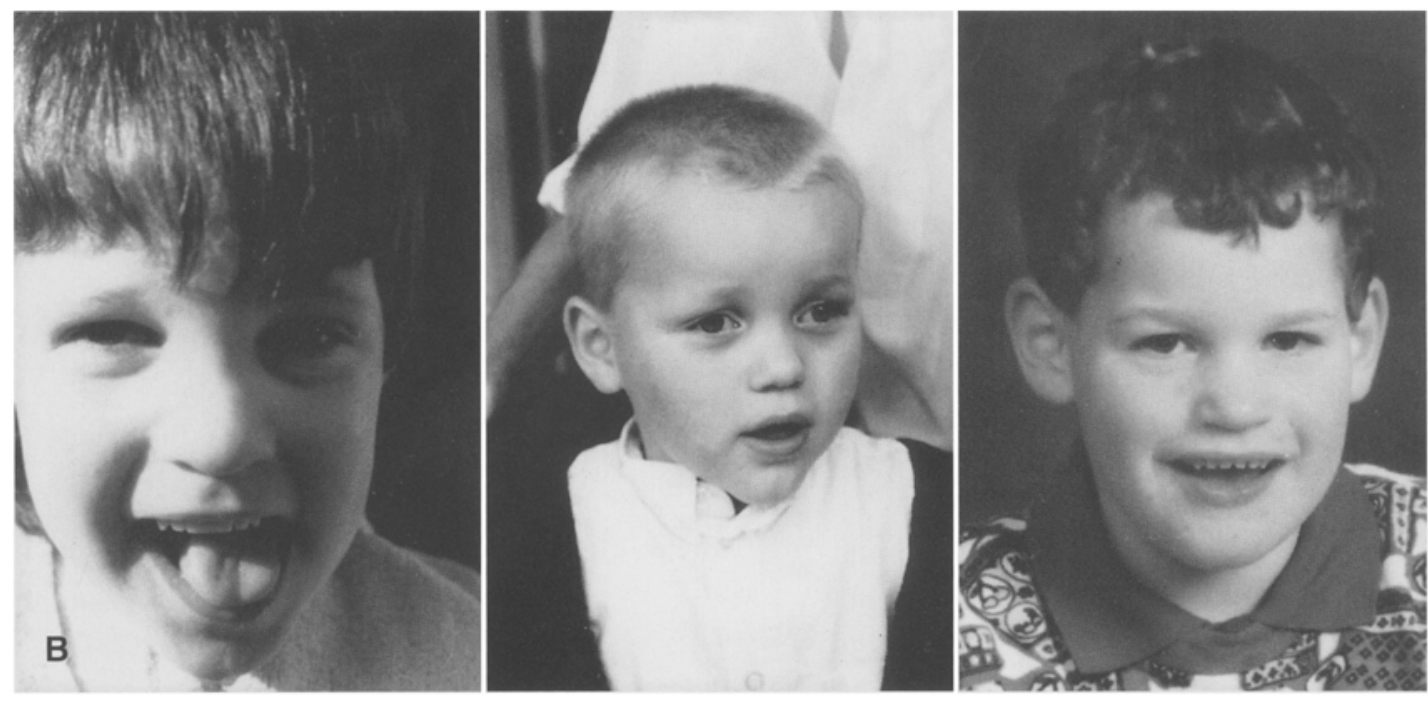


\section{Results and discussion}

We have studied three distantly related patients of an extended inbred family of Dutch ancestry that all fulfill the clinical criteria for AS (Fig. 1). Cytogenetic studies with high resolution chromosome banding showed a normal chromosome 15 pattern in all three patients (data not shown). DNA analysis with 19 markers recognizing 14 loci within $15 q 11-q 13$ was performed for the three AS patients and their parents. Figure 2 shows the presence of two different alleles in patients VIII-5 and VIII-9 at the GABRB 3 locus. The haplotypes of the three AS patients for the 15q11-q13 loci are presented in Fig. 3. No deletions were detected using the seven RFLP markers and 12 polymorphic dinucleotide repeats. Patient VIII-3 demonstrated homozygosity of all markers studied on chromosome 15 , including the telomeric marker cMS620, suggesting paternal UPD (Fig.4). Ten AS patients with UPD have been reported, one with heterodisomy and the remaining nine cases, including our patient, with isodisomy. The etiology of UPD has been suggested to be maternal nondisjunction during maternal meiosis both for AS and PWS (Mutirangura et al. 1993 a). The occurrence of maternal nondisjunction is generally associated with an increased maternal age. This has been found in PWS (Robinson et al. 1991; Mutirangura et al. 1993a) and in AS (Mutirangura et al. 1993a). However, the mother of our AS patient with UPD was only 24 years at the time of birth. Although others have found some evidence for a milder phenotype in UPD patients (Bottani et al. 1994; Gillessen-Kaesbach et al. 1995), the presently described patient with UPD was indistinguishable from deletion-positive AS patients.

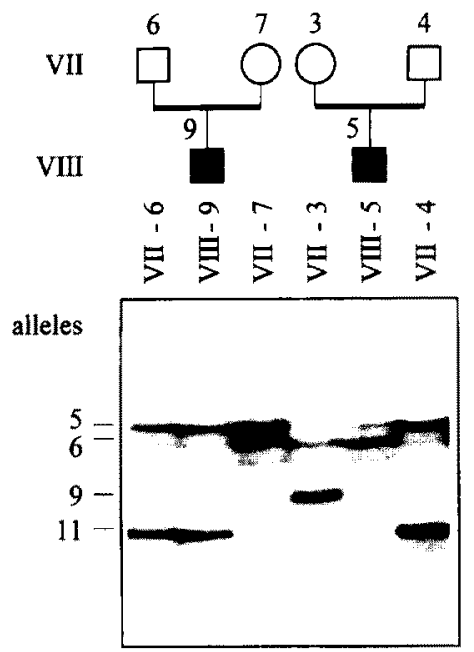

Fig. 2 Detection of heterozygosity at the $G A B R B 3$ gene in patients VIII-5 and VIII-9

Fig. 3 Results of molecular analysis using $15 q 11-q 13$ marker loci. Haplotypes of the three patients show different maternal and paternal contributions in the chromosome $15 q \| 1-q 13$ region

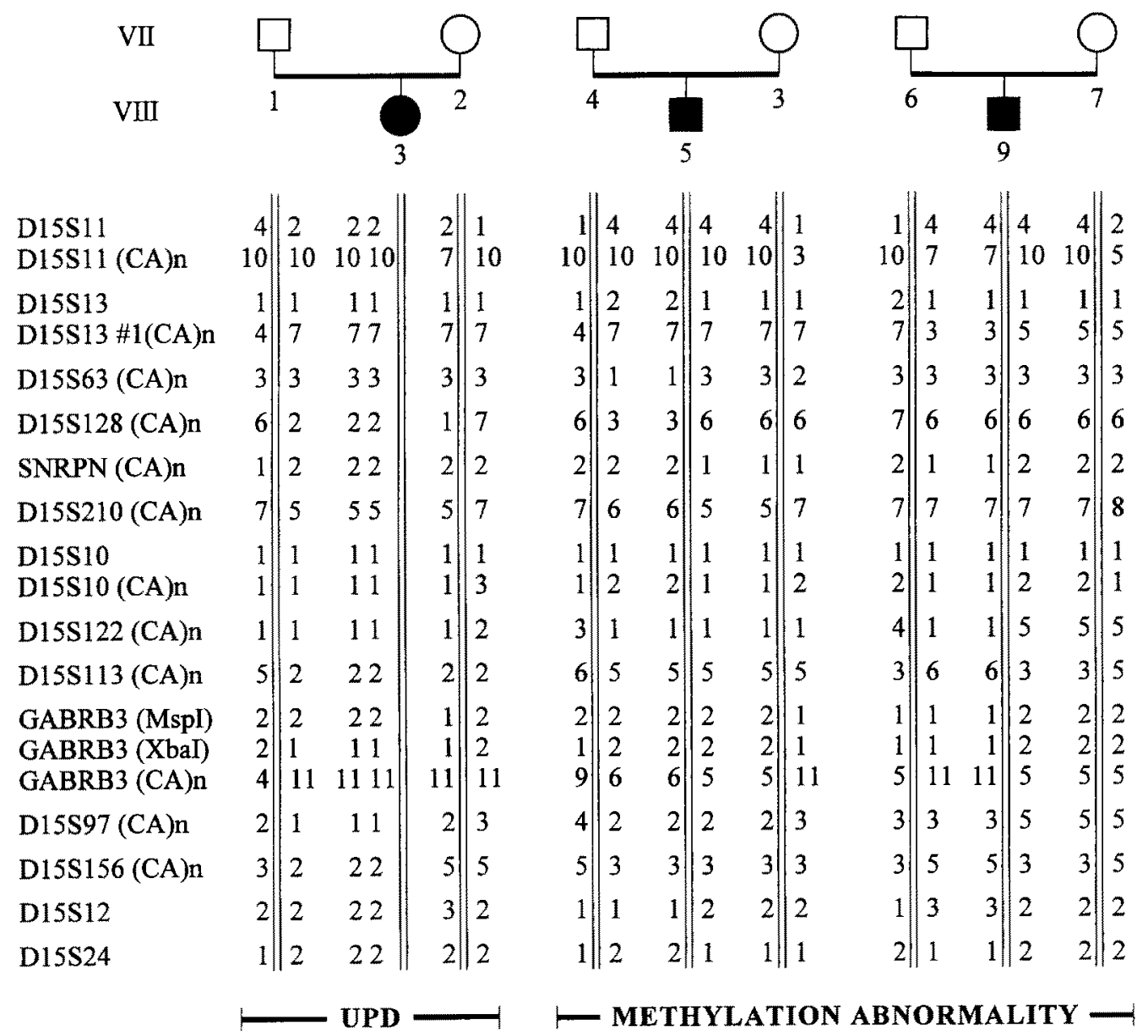




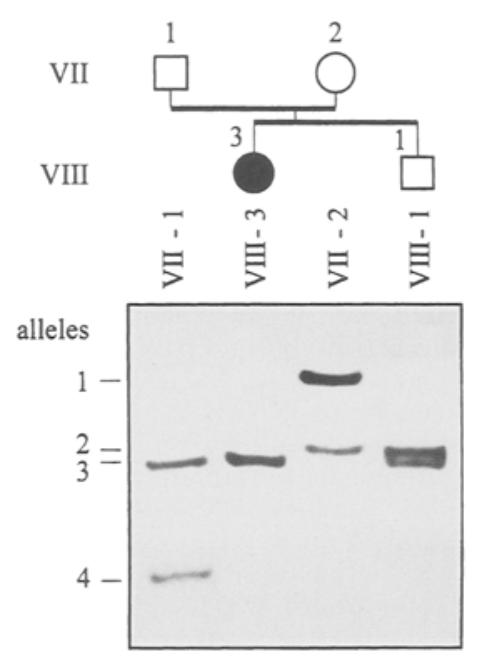

Fig.4 Paternal isodisomy at D15S86 in patient VIII-3, who has none of the maternal alleles 1 and 2

Approximately $65 \%$ of AS patients exhibit interstitial deletions within proximal $15 \mathrm{q}$ and a small minority of AS patients have paternal UPD. In a small subset of AS patients without the classical deletion or UPD, an abnormal methylation pattern within chromosome $15 \mathrm{q} 11-\mathrm{q} 13$ at three different loci SNRPN (exon $\alpha$ ), D15S63 (PW71), and D15S9 (pML34) has been detected (Glenn et al. 1993 a; Horsthemke et al. 1994; Reis et al. 1994 a, b; Sutcliffe et al, 1994). Driscoll et al. (1992) first described methylation differences in ZNF127 at D15S9. A methylation difference at D15S63 (detected with the PW71 probe) has been reported by Dittrich et al. (1992). Glenn et al. (1993 b) and Sutcliffe et al. (1994) found a methylation pattern specific for the maternal homolog within the $\mathrm{CpG}$ island containing exon $\alpha$ of the SNRPN gene. Recently, it has been shown that at least some of these "imprinting mutations" are caused by small deletions proximal from SNRPN (Buiting et al. 1995). Our two AS patients with apparently biparental inheritance of chromosome 15 (VIII-5 and VIII-9) demonstrated a methylation pattern typical of a paternal chromosome on their maternal chromosomes at loci exon $\alpha$ of SNRPN and D15S63 (PW71 probe). In normal individuals, a methylated maternal $4.2-\mathrm{kb}$ fragment and an unmethylated paternal $0.9-\mathrm{kb}$ fragment can be seen using $S N R P N$ exon $\alpha$ hybridization with DNA digested with NotI and XbaI (Sutcliffe et al. 1994; Beuten et al. 1995). Southern hybridization of DNA digested with HindIII and HpaII with PW71 (DI5S63) reveals a 6.0-kb methylated maternal and a 4.4-kb unmethylated paternal allele in normal control samples (Dittrich et al. 1992). For both exon $\alpha$ (Fig. 5) and PW71 a complete absence of the maternal fragment in the two AS patients with imprinting mutations was found. Their respective mothers showed a normal methylation pattern for exon $\alpha$ (Fig. 5) as well as for PW71. Hybridization of pML34 to genomic blots of DNA digested with HindIII and Hpall shows a methylated maternal $6.0-\mathrm{kb}$ and an unmethylated paternal $2.0-$ $\mathrm{kb}$ fragment in normal individuals (B. Horsthemke, per-

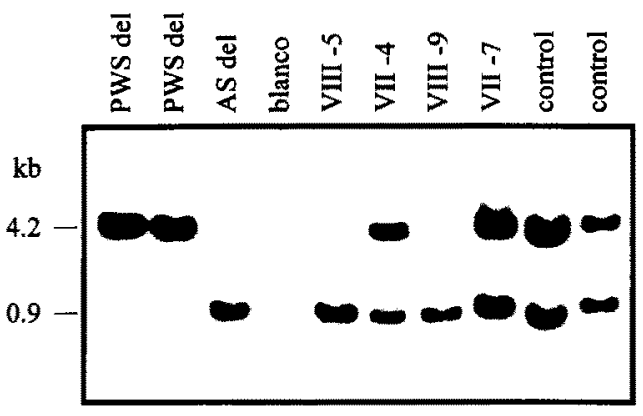

Fig.5 Detection of differential methylation at the SNRPN CpG island in the two Angelman syndrome (AS) patients with biparental inheritance at $15 \mathrm{q} 11-\mathrm{q} 13$. Hybridization of $\mathrm{XbaI} / \mathrm{Not} \mathrm{I}$ doubly digested DNA with exon $\alpha$ of SNRPN reveals two alleles $(4.2 \mathrm{~kb}$ and $0.9 \mathrm{~kb}$ ) in control persons (lanes 9 and 10 ), a maternal methylated 4.2-kb fragment in Prader-Willi syndrome patients with a classical large deletion (lanes 1 and 2), a paternal methylated 0.9-kb fragment in AS patients with a classical large deletion (lane 3). Lanes 5 and 7 are the AS patients with imprinting mutations and their respective mothers (lanes 6 and 8). The DNA from the patients and their mothers was extracted from Epstein-Barr virus-transformed lymphoblasts, whereas the other samples were extracted from peripheral lymphocytes

sonal communication). Using pML34, we found an inconstant methylation pattern in both AS patients with equal or slightly reduced intensity of the maternal band. It has been shown that the methylation of the maternal allele at D15S9 is not complete in AS patients (Dittrich et al. 1992; Driscoll et al. 1992), in contrast to the complete methylation of the maternal homolog of exon $\alpha$ (SNRPN) and PW71 (D15S63) (Dittrich et al. 1992; Sutcliffe et al. 1994). These results correspond with previous reports describing PWS patients and AS patients with an abnormal methylation pattern both for exon $\alpha$ and PW71, whereas D15S9 shows a normal methylation pattern (Glenn et al. 1993 a; Buiting et al. 1994; Reis et al. 1994a).

There are different alternatives to explain the occurrence of three AS patients in this large inbred family. A first possibility is that two independent mutations (UPD in patient VIII-3 and an inherited methylation mutation in patients VIII-5 and VIII-9) occurred. An autosomal dominant methylation mutation (cis-acting on chromosome 15 , or trans-acting on another chromosome), was excluded by pedigree analysis, as inheritance both through maternal and paternal lines exists without phenotypic expression of AS or PWS. A cis-acting methylation mutation, both autosomal dominant as well as autosomal recessive, could further be excluded by haplotype analysis showing different haplotypes for both imprinting mutation AS patients. It is possible, however, that an autosomal recessive trans-acting imprinting mutation segregates in this family. Alternatively, it is possible that three independent mutations are responsible for AS: UPD in patient VIII-3 and two independent cis-acting chromosome 15 imprinting mutations in patients VIII-5 and VIII-9.

Acknowledgements We thank Drs Jeffreys, Lalande and Horsthemke for providing DNA probes, Dr. Ledbetter for primer sequences before publication, K. De Necker for preparation of the 
figures, R. Bernaerts, O. Beck, M. D'Hollander, C. Peerden for skilful technical assistance. This work was supported by a grant of the National Foundation for Scientific Research Belgium (NFWO) to P.J.W.

\section{References}

Beckmann JS, Tomfohrde J, Barnes RI. Williams M, Broux O, Richard I, Weissenbach J, Bowcock AM (1993) A linkage map of human chromosome 15 with an average resolution of $2 \mathrm{cM}$ and containing 55 polymorphic microsatellites. Hum Mol Genet $2: 2019-2030$

Beuten J, Mangelschots K, Buntinx 1, Coucke P, Brouwer OF, Hennekam RCM, Van Broeckhoven C, Willems PJ (1993) Molecular study of chromosome 15 in 22 patients with Angelman syndrome. Hum Genet 90:489-495

Beuten J, Sutcliffe JS, Casey BM, Hennekam RCM, Willems PJ, Beaudet AL (1995) Detection of imprinting mutations in Angelman syndrome using a probe for exon $\alpha$ of SNRPN. Am J Med Genet (in press)

Bottani A, Robinson WP, DeLozier-Blanchet CD, Engel E, Morris MA, Schmitt B, Thun-Hohenstein L, Schinzel A (1994) Angelman syndrome due to paternal uniparental disomy of chromosome 15: a milder phenotype? Am J Med Genet $51: 35-40$

Buiting $\mathrm{K}$, Dittrich B, Robinson WP, Guitart M, Abeliovich D, Lerer 1, Horsthemke B (1994) Detection of aberrant DNA methylation in unique Prader-Willi syndrome patients and its diagnostic implications. Hum Mol Genet 3:893-895

Buiting K, Saitoh S, Gross S, Dittrich B, Schwartz S, Nicholls RD, Horsthemke B (1995) Inherited microdeletions in the Angelman and Prader-Willi syndrome define an imprinting centre on human chromosome 15 . Nat Genet 9:395-400

Butler MG (1990) Prader-Willi syndrome: current understanding of cause and diagnosis. Am J Med Genet 35:319-332

Clayton-Smith J, Pembrey ME (1992) Angelman syndrome. J Med Genet $29: 412-415$

Clayton-Smith J, Webb T, Robb SA, Dijkstra I, Willems P, Lam S, Cheng XJ, Pembrey ME, Malcolm S (1992) A study of siblings with Angelman syndrome: tendency to inherit the same maternal, but not paternal, complement of $15 q 11-q 13$ region. Am $J$ Med Genet $44: 256-260$

Dittrich B, Robinson WP, Knoblauch H, Buiting K, Schmidt K, Gillessen-Kaesbach G, Horsthemke B (1992) Molecular diagnosis of the Prader-Willi and Angelman syndromes by detection of parent-origin specific DNA methylation in 15q11-13. Hum Genet $90: 313-315$

Driscoll DJ, Waters MF, Williams CA, Zori RT, Glenn CC, Avidano KM, Nicholls RD (1992) A DNA methylation imprint, determined by the sex of the parent, distinguishes the Angelman and Prader-Willi syndromes. Genomics 13:917-924

Gillessen-Kaesbach G, Albrecht B. Passarge E, Horsthemke B (1995) Further patient with Angelman syndrome due to paternal disomy of chromosome 15 and a milder phenotype. Am J Med Genet 56:328-329

Glenn CC, Nicholls RD, Robinson WP, Saitoh S, Niikawa N, Schinzel A, Horsthemke B, Driscoll DJ (1993 a) Modification of 15q11-q13 DNA methylation imprints in unique Angelman and Prader-Willi patients. Hum Mol Genet 2:1377-1382

Glenn CC, Porter KA, Jong MTC, Nicholls RD, Driscoll DJ (1993 b) Functional imprinting and epigenetic modification of the human SNRPN gene. Hum Mol Genet 2:2001-2005

Gyapay G, Morissette J, Vignal A, Dib C, Fizames C, Millasseau P, Mare S, Bernardi G, Lathrop M, Weissenbach J (1994) The 1993-94 Généthon human genetic linkage map. Nat Genet 7 : $246-339$

Hamabe J, Fukushima Y, Harada N, Abe K, Matsuo N, Nagai T, Yoshioka A, Tonoki H, Tsukino R, Niikawa N (1991 a) Molecular study of the Prader-Willi syndrome: deletion, RFLP, and phenotype analyses of 50 patients. Am J Med Genet $41: 54-63$
Hamabe J, Kuroki Y, Imaizumi K, Sugimoto T, Fukushima Y, Yamaguchi A, Izumikawa Y, Niikawa N (1991b) DNA deletion and its parental origin in Angelman syndrome patients. Am J Med Genet $41: 64-68$

Horsthemke B, Dittrich B, Gillessen-Kaesbach G, Robinson W, Abeliovich D, Lerer I, Ritzén M, Anvret M, Buiting K (1994) Detection of aberrant DNA methylation in unique Prader-Willi syndrome patients and development of an improved diagnostic test. Med Genetik 1:130

Lindeman R, Kouts S, Woodage T, Smith A, Trent RJ (1991) Dinucleotide repeat polymorphism of D15S10 in the Prader-Willi chromosome region (PWCR). Nucleic Acids Res 19:5449

Malcolm S, Clayton-Smith J, Nichols M, Robb S, Webb T, Armour JAL, Jeffreys AJ, Pembrey ME (1991) Uniparental paternal disomy in Angelman's syndrome. Lancet 337:694-697

Meijers-Heijboer EJ, Sandkuyl LA. Brunner HG, Smeets HJM, Hoogeboom AJM, Deelen WH, van Hemel JO, Nelen MR, Smeets DFCM. Niermeijer MF, Halley DJJ (1993) Linkage analysis with chromosome $15 \mathrm{q} 11-\mathrm{q} 13$ markers shows genomic imprinting in familial Angelman syndrome. J Med Genet 30: $853-857$

Mutirangura A, Greenberg F, Butler MG, Malcolm S, Nicholls RD, Chakravarti A, Ledbetter DH (1993 a) Multiplex PCR of three dinucleotide repeats in the Prader-Willi/Angelman critical region $(15 \mathrm{q} 11-\mathrm{q} 13)$ : molecular diagnosis and mechanism of uniparental disomy. Hum Mol Genet 2:143-151

Mutirangura A, Jayakumar A, Sutcliffe IS, Nakao M. Mckinney MJ, Buiting K. Horsthemke B, Beaudet AL, Chinault AC, Ledbetter DH (1993b) A complete YAC contig of the PraderWilli/Angelman chromosome region $(15 q 11-q 13)$ and refined localization of the SNRPN gene. Genomics 18:546-552

Nelen MR, Van der Burgt CJAM, Nillesen WN, Vis A, Smeets HJM (1994) Familial Angelman syndrome with a crossover in the critical deletion region. Am J Med Genet 52:352-357

Nicholls RD (1993) Genomic imprinting and uniparental disomy in Angelman and Prader Willi syndromes: a review. Am J Med Genet $46: 16-25$

Reis A, Dittrich B, Greger V, Buiting K, Lalande M, GillessenKaesbach G. Anvret M, Horsthemke B (1994 a) Imprinting mutations suggested by abnormal DNA methylation patterns in familial Angelman and Prader-Willi syndromes. Am J Hum Genet $54: 741-747$

Reis A, Tyler K, Greger V, Lalande M, Sperling K (1994b) Imprinting mutations suggested by abnormal DNA methylation patterns in Angelman syndrome - a possible novel class of mutations in man. Med Genetik $1: 93$

Robinson WP, Bottani A, Yagang X, Balakrishman J, Binkert F, Mächler M. Prader A, Schinzel A (1991) Molecular, cytogenetic, and clinical investigations of Prader-Willi syndrome patients. Am J Hum Genet 49:1219-1234

Sutcliffe IS, Nakao M, Christian S, Örstavik KH, Tommerup N, Ledbetter DH, Beaudet AL (1994) Deletions of a differentially methylated $C \mathrm{PG}$ island at the $S N R P N$ gene define a putative imprinting control region. Nat Genet $8: 52 \cdots 58$

Wagstaff J, Shugart YY, Lalande M (1993) Linkage analysis in familial Angelman syndrome. Am J Hum Genet 53: 105-112

Wilkie AOM, Zeitlin HC, Lindenbaum RH, Buckle VJ, FischelGhodsian N, Chui DHK, Gardner-Medwin D. MacGillivray $\mathrm{MH}$, Weatherall DJ, Higgs DR (1990) Clinical teatures and molecular analysis of the $\beta$-thalassemia/mental retardation syndromes. II. Cases without detectable abnormality of the globin complex. Am J Hum Genet 46:1127-1140

Willems PJ, Dijkstra I, Brouwer OF. Smit GPA (1987) Recurrence risk in the Angelman ("happy puppet") syndrome. Am J Med Genet $27: 773-780$

Willams CA, Gray BA, Hendrickson JE, Stone JW, Cantù ES (1989) Incidence of $15 q$ deletions in the Angelman syndrome: a survey of 12 affected persons. Am J Med Gener 32:339-.345 